\title{
Iron(III) Porphyrin Catalyzed [4+2] Cycloaddition of Aldehydes and Dienes
}

Overall transformation:

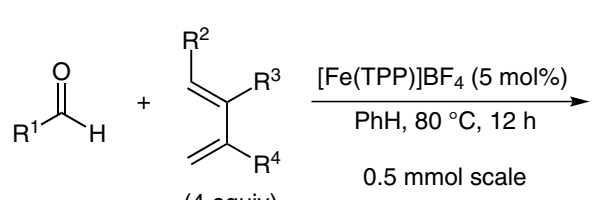

(4 equiv)

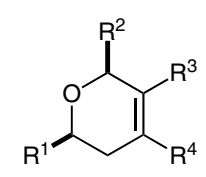

$R^{4}$

(n)

Category

Metal-Catalyzed

Asymmetric

Synthesis and

Stereoselective

Reactions

\section{Key words}

iron

porphyrins

[4+2] cycloaddition

aldehydes

dienes

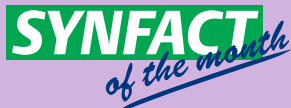

Selected substrate scope:<smiles>CC1C=C(c2ccccc2)CC(c2ccccc2)O1</smiles>

$99 \%$ yield, $d r=92: 8$<smiles>CC1C=C(c2ccc3ccccc3c2)CC(c2ccccc2)O1</smiles>

$88 \%$ yield, $d r=99: 1$<smiles>C1=C(c2ccccc2)CC(CCCC2OCCO2)OC1c1ccccc1</smiles>

$83 \%$ yield, $d r=99: 1$<smiles>CC(C)=CCC/C(C)=C/C1CC(c2ccccc2)=CC(C)O1</smiles>

$72 \%$ yield, $\mathrm{dr}=75: 25$
Significance: The hetero-Diels-Alder reaction is one of the more important and powerful means to construct six-membered heterocycles. Indeed, the method has been utilized for the synthesis of complex natural products and pharmaceutically relevant compounds. However, several limitations exist in these protocols as they tend to require activated aldehydes, electronically rich dienes, and strong Brønsted or Lewis acid additives. It would be highly advantageous for the further development of methods that circumvent these aforementioned limitations.
Comment: The authors report an iron(III) porphyrin catalyzed [4+2] cycloaddition of aldehydes and dienes. This protocol is highly chemo-, regio-, and diastereoselective for the formation of oxygencontaining heterocycles. Yields range from moderate to excellent in generally high levels of regioand diastereocontrol. It is noteworthy that the reaction can be performed chemoselectively in the presence of potentially reactive olefins. 